\title{
Produção de óleo essencial de Melissa officinalis $L$. em diferentes épocas, sistemas de cultivo e adubações
}

\author{
LUZ, J.M.Q.'; SILVA, S.M.'; HABBER, L.L.2; MARQUEZ, M.O.M. ${ }^{3}$. \\ 'UFU-ICIAG Universidade Federal de Uberlândia - Instituto de Ciências Agrárias, Campus Umuarama,

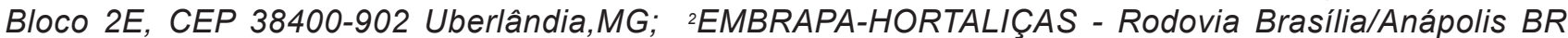 \\ 060 Km 09 Gama - DF; ' $I A C$ - Instituto Agronômico de Campinas, Av. Barão de Itapura, 1481 - Caixa \\ Postal 28 - 13012-970 - Campinas - SP. sergiomacedosilva@yahoo.com.br
}

\begin{abstract}
RESUMO: Os objetivos deste trabalho foram avaliar a biomassa, o rendimento e a composição de óleo essencial de Melissa officinalis L. submetida a diferentes épocas de plantio, sistemas de cultivo, e adubações. O delineamento experimental foi o de blocos casualizados (DBC), em esquema fatorial $2 \times 2 \times 2$, sendo duas épocas de plantio (verão e inverno), dois sistemas de cultivo (estufa e campo), e dois tipos de adubação (mineral e orgânica). A colheita consistiu no corte de todas as plantas da parcela útil. Após a colheita, foi avaliada a massa fresca foliar, a altura de plantas, o comprimento e largura das folhas. A extração de óleo essencial foi realizada por hidrodestilação e a composição química foi analisada em cromatógrafo gasoso acoplado a espectrômetro de massas. Das substâncias encontradas, prevaleceram como constituintes majoritários os monoterpenos geranial e neral na colheita de verão, e geranial, neral e citronelal na colheita de inverno. As condições do ambiente protegido e do verão propiciaram melhor biomassa de melissa, maior rendimento de óleo essencial, e maior taxa do constituinte citral.
\end{abstract}

Palavras chave: melissa, cultivo protegido, óleo essencial.

\begin{abstract}
Essential oil of Melissa officinalis L. at differents seasons, systems of planting and fertilizations. The objectives of this study were to evaluate the biomass, yield and composition of essential oil of Melissa officinalis L. under differents seasons, systems of planting and fertilizations. The experimental design was a randomized block design (RBD), in a factorial $2 \times 2 \times 2$ with two seasons of harvest (summer and winter), two systems of planting (greenhouse and field) and two types of fertilizer (mineral and organic). The harvest consisted of cutting all plants of central line. After harvest, it were evaluated the leaf fresh weight, height of the plant, length and width of the leaves. The essential oil extraction was performed by hydrodistillation and the chemical composition was performed by gas chromatography coupled by mass spectrometry. The major constituents were geranial and neral in summer harvest and geranial, neral and citronellal in winter harvest. The conditions of the greenhouse and the summer presented the better biomass, higher yield of oil and higher rate of citral.
\end{abstract}

Keywords: lemon balm, greenhouse, essential oil.

\section{INTRODUÇÃO}

Melissa officinalis $L$. pertence à família das Lamiáceas. Suas folhas são utilizadas para chá e condimentos e seu óleo essencial é largamente utilizado pela indústria farmacêutica por possuir atividade antioxidativa, antibiótica, antifúngica, antibacteriana e sedativa. A melissa é uma planta que prefere climas temperados e não resiste a geadas e vento frio, se adapta melhor a lugares parcialmente sombreados, não tolerando calor excessivo (Lorenzi \& Matos, 2002).

Análises químicas dos extratos de partes aéreas de melissa evidenciaram presença de monoterpenos aromáticos, como citral, citronelal, geraniol, cânfora, além de mucilagem, taninos, saponinas e resinas (Blank et al., 2006). Os teores de óleo essencial de melissa, obtidos por hidrodestilação são habitualmente muito baixos $(0,02$ a $0,40 \%)$, o que o coloca em uma das classes mais preciosas de óleo essencial, apresentando alto valor de mercado, comparado aos preços do óleo essencial de rosas e de outras aromáticas (Paviani, 2004).

Recebido para publicação em 05/05/2011 
Existe um interesse econômico relativo aos componentes aromáticos que direciona a atenção para a seleção de espécies comercialmente cultivadas, considerando quantidade e qualidade das substâncias voláteis. Nesse sentido, o Brasil tem lugar de destaque na produção de óleos essenciais, ao lado da Índia, China e Indonésia. No Brasil, o banco de dados citado por Maia e Andrade, 2009, tem registro de mais de 1.200 espécies aromáticas, fornecendo informações importantes e valiosas sobre o potencial econômico dessas plantas.

Quanto ao cultivo, o teor e a composição do óleo essencial das plantas aromáticas dependem de diferentes fatores. As condições do solo, clima, origem geográfica, época de colheita, fertilizantes e a nutrição mineral podem afetar consideravelmente a produção e a qualidade do óleo essencial (Sales et al., 2009). Experimentos sobre condições bem controladas têm demonstrado que variações no ambiente (temperatura, irradiação e fotoperíodo) podem influenciar positivamente ou negativamente no rendimento da biomassa e na qualidade do óleo essencial em plantas aromáticas (Brant et al., 2009).

Como a grande maioria das culturas, as plantas aromáticas devem responder positivamente a um adequado programa de produção, envolvendo manejo correto do solo e das próprias espécies. Portanto, o suprimento de nutrientes, deve basearse em análises químicas do solo e de tecidos das plantas, associado a outras práticas culturais, para promover resultados, como boa produtividade, lucratividade e proteção ambiental (Amaral et al., 2010).

Dessa forma, os objetivos deste trabalho foram avaliar a produção de biomassa, o rendimento e a composição de óleo essencial de Melissa officinalis L. (Lamiaceae), submetida a diferentes épocas de colheita, tipos de adubações e sistemas de cultivo, nas condições de Uberlândia, MG, Brasil.

\section{MATERIAL E MÉTODOS}

O experimento foi conduzido em campo e em estufa na Fazenda Experimental do Glória (1857' S e $48^{\circ} 12^{\prime} \mathrm{W}$ ), pertencente à Universidade Federal de Uberlândia (UFU). Segundo a classificação climática de Köppen, o clima da região é caracterizado como Aw (megatérmico), apresentando durante o ano duas estações bem definidas, inverno seco e verão chuvoso. O solo presente na área de estudo é Latossolo Vermelho Distrófico e Nitossolo Vermelho Eutrófico (Embrapa, 2013).

O delineamento experimental foi de blocos casualizados (DBC), em esquema fatorial $2 \times 2$ $x 2$, com dez repetições, sendo duas épocas de colheita (verão e inverno), dois sistemas de cultivo (estufa e campo) e dois tipos de adubação (mineral e orgânica). Os espaçamentos utilizados foram 80 $\mathrm{cm}$ entre linhas e $50 \mathrm{~cm}$ entre plantas. As parcelas no campo e na estufa foram de três linhas de 10 plantas, sendo a parcela útil constituída pela linha central.

O experimento de verão ocorreu entre os meses de outubro de 2009 e fevereiro de 2010 e o experimento de inverno entre os meses de maio e agosto de 2010. Entre os meses de outubro e dezembro de 2009 e janeiro e fevereiro de 2010, as médias da umidade relativa do ar foram $77,3 \%$ e $75,38 \%$, respectivamente. Entre os meses de maio e agosto de 2010 , a média da umidade relativa do ar foi $57,33 \%$. Os tratos culturais consistiram em irrigações por aspersão, a cada dois dias e capinas periódicas para controle de plantas invasoras.

As mudas foram produzidas em bandejas de poliestireno com 200 células, usando substrato Plantmax $®$ e sementes adquiridas no comércio da cidade. Na adubação orgânica foram utilizados $8 \mathrm{~kg}$ $\mathrm{m}^{-2}$ de esterco de curral curtido para os 2 sistemas de cultivo, conforme recomendação de Martins e Figueiredo (2009) para hortaliças e aromáticas. O resultado da análise química do esterco de curral curtido pode ser observado na Tabela 1. Na adubação mineral foram utilizados $40 \mathrm{~g} \mathrm{~m}^{-1}$ de NPK $(4,14,8)$ e $7,2 \mathrm{~g} \mathrm{~m}^{-1}$ de $\mathrm{KCl}$ para campo e $24 \mathrm{~g} \mathrm{~m}^{-1}$ de NPK $(4,14,8), 8,8 \mathrm{~g} \mathrm{~m}^{-1}$ de KCl e 1,6 $\mathrm{g} \mathrm{m}^{-1}$ de uréia para estufa. Tais doses foram ajustadas conforme recomendação de Furlan (2007) para cultivo de plantas condimentares. As adubações foram realizadas 30 dias antes do plantio. O plantio ocorreu 45 dias após a semeadura e a colheita ocorreu aos 120 dias após o plantio, ambos no período matutino nas duas estações. A colheita consistiu no corte de todas as plantas da parcela útil, feito a $10 \mathrm{~cm}$ do solo (Blank et al., 2005). Após a colheita, foi avaliada a massa fresca foliar, altura de plantas, comprimento e largura das folhas.

A extração de óleo essencial foi realizada por hidrodestilação, em aparelho tipo Clevenger, por duas horas. Posteriormente, as amostras de óleo foram armazenadas em frascos de vidro e mantidas no freezer $\mathrm{a}-10^{\circ} \mathrm{C}$. As análises químicas dos óleos essenciais foram realizadas no Laboratório de Fitoquímica do Instituto Agronômico de Campinas (IAC), conduzidas em cromatógrafo a gás acoplado a espectrômetro de massas (CG/EM) (Shimadzu, QP-5000), utilizando-se o seguinte programa de temperatura: $60^{\circ}-240^{\circ} \mathrm{C}, 3^{\circ} \mathrm{C} / \mathrm{min}$ e split $1 / 20$. A identificação química de cada substância foi determinada por comparação dos seus espectros de massas, com o banco de dados do sistema CG/ EM (NIST 62). Por comparação dos índices de retenção (Adams, 2007), obtidos por meio da coinjeção do óleo essencial com uma mistura padrão de n-alcanos $\left(\mathrm{C}_{9} \mathrm{H}_{20}-\mathrm{C}_{25} \mathrm{H}_{52}\right.$ Sigma Aldrich, 99\%) e dados da literatura (McLafferty \& Stauffer, 1989). As 
etapas de extração, quantificação e identificação dos compostos essenciais foram realizadas ao final de cada colheita. Os dados obtidos foram submetidos a uma análise de variância conjunta e as médias comparadas pelo teste de Tukey $(p \leq 0,05)$, com auxílio do programa estatístico SISVAR ${ }^{\circledast}$ (Ferreira, 2000).

\section{RESULTADOS}

\section{Análise de biomassa}

A colheita de verão e o cultivo na estufa proporcionaram as melhores condições para o bom desenvolvimento de Melissa officinalis L. As maiores médias para altura foram encontradas na estufa (Tabela 2) com adubação orgânica (Tabela 3). Para comprimento e largura foliar, o plantio na estufa apresentou maior tamanho de lâmina foliar, mas não apresentou diferença significativa entre as épocas de colheita (Tabela 2). A adubação orgânica também favoreceu maior desenvolvimento da lâmina foliar, principalmente no inverno (Tabela 3). Na colheita de verão, a biomassa foliar (Tabela 4) foi maior na estufa do que no campo, com média de $305,34 \mathrm{~g}$ planta ${ }^{-1}$. Na colheita de inverno, a biomassa foliar na estufa também foi maior com a adubação orgânica, apresentando média de $107 \mathrm{~g}_{\text {planta }}{ }^{-1}$.

\section{Análise do óleo essencial}

Em relação ao rendimento de óleo essencial, os resultados não apresentaram diferença significativa (Tabela 5), apesar do plantio na estufa utilizando adubação orgânica durante o verão ter apresentado o maior valor, $14,8 \mathrm{~L} \mathrm{ha}^{-1}$. Como os resultados de rendimento são influenciados pela produção de biomassa, e sendo esta maior na estufa, principalmente no verão, esperava-se que o rendimento de óleo essencial fosse proporcional ao aumento de biomassa por área.

Quanto à composição química do óleo, as plantas cultivadas em ambiente protegido e no campo (Tabela 6) com adubação mineral e orgânica apresentaram a mesma composição. Das substâncias encontradas, $80 \%$ foram identificadas, prevalecendo como majoritários geranial, geraniol, neral, citronelal, cariofileno e linalol nas duas épocas de colheita (Figuras 1 e 2).

Tabela 1. Resultado da análise química do esterco de curral curtido utilizado para adubação orgânica dos experimentos de verão e inverno. UFU, Uberlândia, 2011.

\begin{tabular}{lcc}
\hline Análises & Unidade & Valor \\
\hline $\mathrm{pH}$ CaCl2 0,01M & $\mathrm{pH}$ & 6,10 \\
Nitrogênio Total & $\%$ & 1,76 \\
Mat. Orgânica Resistente a Compostagem & $\%$ & 22,99 \\
Carbono Orgânico & $\%$ & 29,79 \\
Relação C/N (C Orgânico e N Total) & --- & $17 / 1$ \\
Fósforo ( $\mathrm{P}_{2} \mathrm{O}_{5}$ Total) & $\%$ & 0,46 \\
Potássio ( $\mathrm{K}_{2} \mathrm{O}$ Total) & $\%$ & 1,95 \\
Cálcio (Ca Total) & $\%$ & 2,14 \\
Magnésio (Mg Total) & $\%$ & 0,19 \\
Enxofre (S Total) & $\%$ & 0,11 \\
Boro (B Total) & $\mathrm{mg} \mathrm{kg}^{-1}$ & 36,00 \\
Cobre (Cu Total) & $\mathrm{mg} \mathrm{kg}^{-1}$ & 16 \\
Ferro (Fe Total) & $\mathrm{mg} \mathrm{kg}^{-1}$ & 2898 \\
Manganês (Mn Total) & $\mathrm{mg} \mathrm{kg}^{-1}$ & 48 \\
Zinco (Zn Total) & $\mathrm{mg} \mathrm{kg}^{-1}$ & 43 \\
Sódio (Na Total) & $\mathrm{mg} \mathrm{kg}^{-1}$ & 450 \\
CTC (Capacidade Troca de Cátion) & $\mathrm{Cmolc} \mathrm{kg}^{-1}$ & $\mathrm{~ns}$ \\
\hline
\end{tabular}

Tabela 2. Altura de plantas, comprimento e largura de folhas de Melissa officinalis L. sobre interação de sistemas de cultivo e épocas de colheita. UFU, Uberlândia, 2011.

\begin{tabular}{llllllllll}
\hline & Altura $(\mathrm{cm})$ & \multicolumn{3}{l}{ Comprimento $(\mathbf{c m})$} & \multicolumn{3}{c}{ Largura $(\mathbf{c m})$} \\
\cline { 2 - 9 } Épocas & Estufa & Campo & Média & Estufa & Campo & Média & Estufa & Campo & Média \\
\hline Verão & $81.00 \mathrm{Aa}$ & $53.40 \mathrm{Ba}$ & 67.20 & $7.10 \mathrm{Aa}$ & $4.50 \mathrm{Bb}$ & 5.80 & $6,20 \mathrm{Aa}$ & $3.20 \mathrm{Bb}$ & 4.70 \\
Inverno & $48.40 \mathrm{Ab}$ & $34.30 \mathrm{Bb}$ & 41.35 & $7.30 \mathrm{Aa}$ & $6.90 \mathrm{Ba}$ & 7.10 & $6,00 \mathrm{Aa}$ & $5.30 \mathrm{Ba}$ & 5.65 \\
\hline CV\% & 8,54 & & \multicolumn{3}{c}{11.06} & & & 8.17 & \\
\hline
\end{tabular}

Médias seguidas por letras distintas, maiúsculas na linha e minúsculas na coluna, diferem entre si pelo teste de Tukey, a 0,05 de significância.

Rev. Bras. Pl. Med., Campinas, v.16, n.3, p.552-560, 2014. 
Tabela 3. Altura de plantas, comprimento e largura de folhas de Melissa officinalis L. sobre interação de épocas de colheita e tipos de adubação. UFU, Uberlândia, 2011.

\begin{tabular}{llllllllll}
\hline & \multicolumn{2}{l}{ Altura(cm) } & \multicolumn{3}{l}{ Comprimento (cm) } & & \multicolumn{3}{l}{ Largura(cm) } \\
\cline { 2 - 10 } Épocas & Mineral & Orgânica & Média & Mineral & Orgânica & Média & Mineral & Orgânica & Média \\
\hline Verão & $60.80 \mathrm{Ba}$ & $73.60 \mathrm{Aa}$ & 67.20 & $5,60 \mathrm{Bb}$ & $6,00 \mathrm{Ab}$ & 5.80 & $4.50 \mathrm{Ab}$ & $4.90 \mathrm{Ab}$ & 4.70 \\
Inverno & $31.80 \mathrm{Bb}$ & $50.90 \mathrm{Ab}$ & 41.35 & $6,20 \mathrm{Bb}$ & $8,00 \mathrm{Aa}$ & 7.10 & $5.10 \mathrm{Ba}$ & $6.20 \mathrm{Aa}$ & 5.65 \\
\hline CV\% & 8,54 & & & 11.06 & & & 8.17 & & \\
\hline
\end{tabular}

Médias seguidas por letras distintas, maiúsculas na linha e minúsculas na coluna, diferem entre si pelo teste de Tukey, a 0,05 de significância.

Tabela 4. Massa fresca foliar de Melissa officinalis L. colhida no verão e no inverno. UFU, Uberlândia, 2011.

\begin{tabular}{lllllll}
\hline & \multicolumn{2}{l}{ Verão $(\mathrm{g}$ planta-1) } & \multicolumn{4}{l}{ Inverno (g planta-1) } \\
\cline { 2 - 7 } Sistema de cultivo & Mineral & Orgânica & Média & Mineral & Orgânica & Média \\
\hline Estufa & 276,88 & 333,8 & $305,34 \mathrm{a}$ & $47,48 \mathrm{aB}$ & $168,32 \mathrm{aA}$ & 107,90 \\
Campo & 104,84 & 148,4 & $126,62 \mathrm{~b}$ & $55,76 \mathrm{aA}$ & $90,80 \mathrm{bA}$ & 73,28 \\
\hline Média & $190,86 \mathrm{~A}$ & $241,1 \mathrm{~A}$ & & 51,62 & 129,56 & \\
\hline CV\% & 25.09 & & & 39,12 & & \\
\hline
\end{tabular}

Médias seguidas por letras distintas, maiúsculas na linha e minúsculas na coluna, diferem entre si pelo teste de Tukey, a 0,05 de significância.

Tabela 5. Rendimento de óleo essencial $\left(L h^{-1}\right)$ de massa fresca de Melissa officinalis $L$. sobre interação de sistemas de cultivo e tipos de adubação. UFU, Uberlândia, 2011.

\begin{tabular}{llrrrrr}
\hline \multirow{2}{*}{ Sistema de cultivo } & \multicolumn{5}{l}{ Inverno } & \multicolumn{4}{l}{ Verão } \\
\cline { 2 - 7 } & \multicolumn{2}{l}{ Adubação } & \multicolumn{4}{l}{ Adubação } \\
& Mineral & Orgânica & Média & Mineral & Orgânica & Média \\
\hline Estufa & 7,20 & 7,60 & $\mathbf{7 , 4 0 a}$ & 11,8 & 14,8 & $\mathbf{1 2 , 6 a}$ \\
Campo & 6,80 & 6,00 & $\mathbf{6 , 4 0 a}$ & 10,4 & 11,2 & $\mathbf{1 0 , 8 a}$ \\
\hline Média & $7,0 \mathrm{~A}$ & $6,80 \mathrm{~A}$ & & $11,1 \mathrm{~A}$ & $13,0 \mathrm{~A}$ & \\
\hline DMS & 4,08 & & & 7,00 & & \\
\hline CV\% & 48,42 & & & 59,69 & & \\
\hline
\end{tabular}

Médias seguidas por letras distintas, maiúsculas na linha e minúsculas na coluna, diferem entre si pelo teste de Tukey, a 0,05 de significância.

O constituinte geranial apresentou as maiores porcentagens relativas, fator de grande importância ao se considerar um óleo comercial. As duas colheitas proporcionaram ganhos na produção deste constituinte, com maior destaque para a colheita do verão (Tabela 7).

Para o constituinte químico neral, a colheita no verão proporcionou as maiores porcentagens relativas (Tabela 8).

Como observado, a colheita do inverno não favoreceu a produção de citral (neral + geranial). Nessa época, houve aumento da porcentagem relativa de outros constituintes como citronelal, citronelol, citronelato de metila, cariofileno e óxido de cariofileno (Tabela 6). Por outro lado, a maior porcentagem de citronelal foi proporcionada na colheita de inverno e as menores taxas foram proporcionadas na colheita do verão (Tabela 9).

\section{DISCUSSÃO}

A produção de biomassa de melissa foi consideravelmente maior na colheita de verão em relação à colheita de inverno. Na primeira época, a temperatura média, a radiação solar e a umidade relativa do ar foram elevadas, propiciando assim conversão da luz em assimilados para o desenvolvimento da biomassa. Resultados semelhantes foram encontrados por Ehlert (2003) no cultivo de Lippia alba em diferentes épocas, onde os fatores climáticos contribuíram para o desenvolvimento das plantas na época quente e úmida.

$\mathrm{Na}$ colheita de inverno, as condições do clima não foram tão favoráveis ao cultivo de Melissa officinalis L., principalmente no campo em relação à estufa. Essas condições se referem ao tempo seco, baixa umidade relativa do ar, média de $59,27 \%$ no inverno, falta de chuvas, baixa umidade do solo, queda de temperatura, principalmente noturna e vento frio. Todos esses fatores influenciaram no crescimento da melissa, desenvolvendo plantas menores com pouca produção de biomassa, propiciando maior desenvolvimento da lâmina foliar nesse período (Tabela 3), para maior captação 
Tabela 6. Porcentagem relativa média (\%) de constituintes encontradas no óleo essencial de folhas de Melissa officinalis L., submetida à interação de sistemas de cultivo e tipos de adubação em duas colheitas. IAC, Campinas, SP, 2011.

\begin{tabular}{|c|c|c|c|c|c|c|c|c|c|c|}
\hline \multirow{3}{*}{ Substâncias } & \multicolumn{4}{|l|}{ Verão } & \multicolumn{4}{|c|}{ Inverno } & \multirow{3}{*}{ IK lit 3} & \multirow{3}{*}{$\mathrm{IK}^{4}$} \\
\hline & \multicolumn{4}{|c|}{ Massa fresca } & \multicolumn{4}{|c|}{ Massa fresca } & & \\
\hline & $\mathrm{CM}^{1}$ & $\mathrm{CO}$ & EM & EO & $\mathrm{CM}^{1}$ & $\mathrm{CO}$ & EM & EO & & \\
\hline Linalol & 0,86 & 1,12 & 1,04 & 1,33 & 3,42 & 1,66 & 2,31 & 2,42 & 1110 & 1107 \\
\hline Nonenal & 0,13 & 0,14 & $\operatorname{tr}^{2}$ & $\operatorname{Tr}$ & 0,51 & 0,56 & 0,47 & 0,35 & 1126 & 1129 \\
\hline Citronelal & 10,69 & 4,18 & 1,14 & 0,55 & 19,32 & 35,43 & 24,89 & 17,57 & 1181 & 1179 \\
\hline Cis-isocitral & 1,18 & 1,37 & 1,44 & 1,28 & 0,40 & 0,52 & 0,75 & 0,84 & 1228 & 1227 \\
\hline Trans-isocitral & 1,69 & 2,01 & 1,98 & 1,82 & 0,6 & 0,726 & 1,04 & 1,17 & 1243 & 1241 \\
\hline Citronelol & 0,39 & 0,2 & 0,09 & 0,1 & 3,37 & 3,42 & 0,70 & 0,72 & 1254 & 1249 \\
\hline Neral & 31,33 & 35,04 & 32,34 & 33,00 & 9,49 & 15,49 & 20,56 & 25,24 & 1260 & 1264 \\
\hline Geraniol & $\operatorname{tr}$ & 0,39 & 0,59 & 0,96 & 3,28 & 2,62 & 0,51 & 0,84 & 1274 & 1272 \\
\hline Citronelato de metila & $\operatorname{tr}$ & 0,20 & 0,12 & $\operatorname{Tr}$ & 4,07 & 4,02 & 3,10 & 1,44 & 1315 & 1311 \\
\hline Geranial & 47,97 & 50,63 & 56,03 & 55,13 & 16,61 & 28,04 & 38,54 & 43,15 & 1323 & 1325 \\
\hline Geranato de metila & 0,45 & 0,29 & 0,32 & 0,64 & 0,30 & 0,28 & 0,33 & 0,22 & 1414 & 1410 \\
\hline Acetato de geranila & $\operatorname{tr}$ & 0,30 & 0,49 & 0,87 & 1,18 & 1,52 & 0,91 & 0,44 & 1417 & 1413 \\
\hline Cariofileno & 1,89 & 2,17 & 2,39 & 2,58 & 3,66 & 5,15 & 3,69 & 3,32 & 1420 & 1425 \\
\hline Acetona de geranila & 0,12 & 0,12 & $\operatorname{tr}$ & $\operatorname{Tr}$ & 2,18 & $\operatorname{tr}$ & 0,28 & 0,22 & 1484 & 1487 \\
\hline Oxido de cariofileno & 0,39 & 0,28 & 0,11 & 0,15 & 3,55 & $\operatorname{tr}$ & $\operatorname{tr}$ & $\operatorname{tr}$ & 1635 & 1633 \\
\hline
\end{tabular}

Tratamentos: CM: Campo / mineral; CO: Campo/orgânica; EM: Estufa/mineral; EO: Estufa/orgânica. ${ }^{2 t r: ~ p o r c e n t a g e m ~ r e l a t i v a ~ i n f e r i o r ~ a ~}$ $0,11 \%$. 3́́ndice de Retenção de Kovats referente à literatura; ${ }^{4}$ ndice de Retenção calculado.

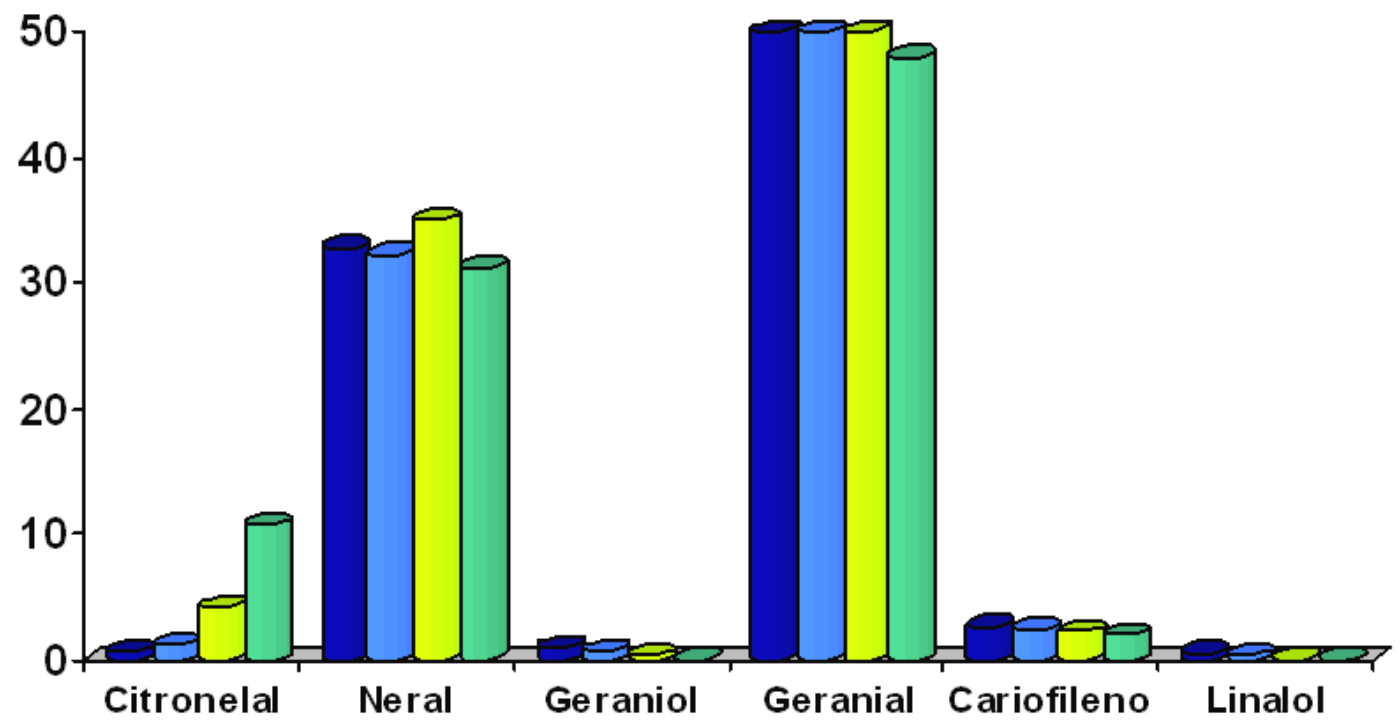

Figura 1. Porcentagem relativa média (\%) dos constituintes químicos majoritários do óleo essencial de Melissa officinalis L. da época de verão. As cores se referem aos tratamentos: Estufa/Orgânica: azul escuro; Estufa/ Química: azul claro; Campo/Orgânica : verde claro; Campo/Química : verde escuro.

possível de luz, incluindo também as plantas da estufa.

O período seco no cerrado apresenta ventos fortes e frios durante o dia e à noite e, esses ventos, exercem influência direta em espécies que apresentam estruturas histológicas de estocagem de óleo na superfície como as espécies da família
Lamiaceae (Valmorbida et al., 2006). Sari \& Ceylan (2002) cultivaram Melissa officinalis L. na Turquia a $10 \mathrm{~m}$ de altitude, com precipitação média anual de $550 \mathrm{~m}$, com temperatura média de 16,5。 C e obtiveram plantas com altura média de 47,58 $\mathrm{cm}$ e massa fresca de $2.869 \mathrm{~kg} \mathrm{ha}^{-1}$. Apesar dos resultados serem inferiores ao do presente estudo, 


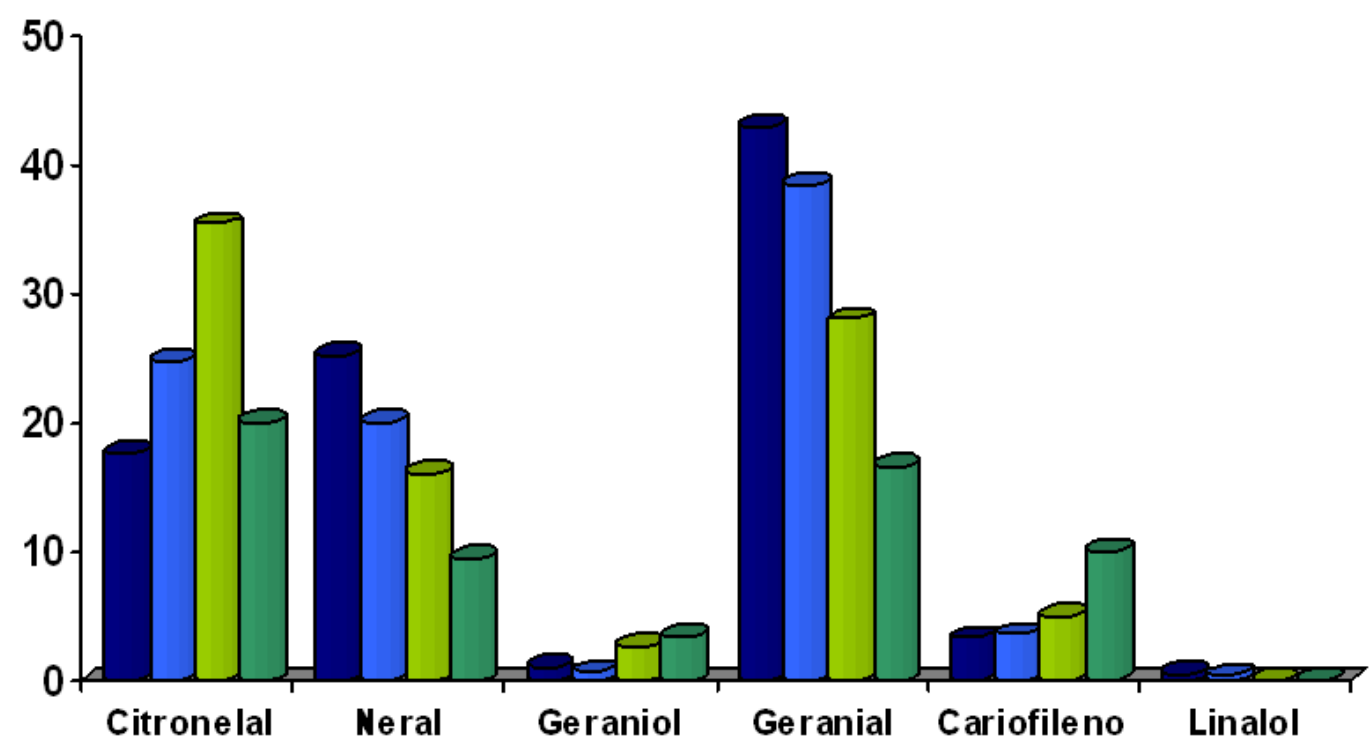

Figura 2. Porcentagem relativa média (\%) dos constituintes químicos majoritários do óleo essencial de Melissa officinalis $L$. da época de inverno. As cores se referem aos tratamentos: Estufa/Orgânica: azul escuro; Estufa/ Química: azul claro; Campo/Orgânica : verde claro; Campo/Química : verde escuro.

Tabela 7. Porcentagem relativa média (\%) de geranial obtido de folhas frescas de Melissa officinalis L. em função de sistemas de cultivos, adubações e épocas de colheita. UFU, Uberlândia, 20111.

\begin{tabular}{lllll}
\hline & Sistemas & \multicolumn{3}{l}{ Adubação } \\
\hline Épocas & Estufa & Campo & Mineral & Orgânica \\
\hline Inverno & $40.84 \mathrm{Ba}$ & $22.32 \mathrm{Bb}$ & $27.57 \mathrm{Bb}$ & $35.59 \mathrm{Ba}$ \\
\hline Verão & $55.76 \mathrm{Aa}$ & $49.30 \mathrm{Ab}$ & $52.00 \mathrm{Aa}$ & $53.06 \mathrm{Aa}$ \\
\hline $\mathbf{C V}(\%)$ & 8.62 & & & \\
\hline Médias seguidas por letras distintas maiúsculas na coluna e minúsculas na linha se diferem pelo Teste de Tukey a 5\% de probabilidade
\end{tabular}

Tabela 8. Porcentagem relativa média (\%) de neral obtido de folhas frescas de Melissa officinalis L. em função de sistemas de cultivos, adubações e épocas de plantio. UFU, Uberlândia, 2011.

\begin{tabular}{lllll}
\hline & Sistemas & \multicolumn{3}{c}{ Adubação } \\
\hline Época & Estufa & Campo & Mineral & Orgânica \\
\hline Inverno & $22.882 \mathrm{Ba}$ & $12.497 \mathrm{Bb}$ & $15.007 \mathrm{Bb}$ & $20.372 \mathrm{Ba}$ \\
\hline Verão & $32.578 \mathrm{Aa}$ & $33.216 \mathrm{Aa}$ & $31.838 \mathrm{Ab}$ & $33.956 \mathrm{Aba}$ \\
\hline \multicolumn{1}{c}{$\mathrm{CV}(\%)$} & 8.24 & & & \\
\hline
\end{tabular}

'Médias seguidas por letras distintas maiúsculas na coluna e minúsculas na linha se diferem pelo Teste de Tukey a 5\% de probabilidade.

os autores ainda consideraram estas condições apropriadas para o cultivo de melissa na Turquia.

Ozturk et al. (2004) também cultivando Melissa officinalis L. na Turquia, sob estresse hídrico, obtiveram baixos valores para altura, na faixa de 39 a $58 \mathrm{~cm}$. Neste estudo, demonstraram que a Melissa officinalis L. é altamente tolerante ao déficit hídrico e moderadamente tolerante ao stress salínico e apresenta alto potencial para ser cultivada até mesmo em regiões como a Turquia, com alto nível de salinidade no solo. Além disso, o estudo mostrou que a melissa foi mais tolerante ao sal e à falta de umidade comparada a outras plantas como milho, beterraba, batata, espinafre e tomate.

O cultivo em estufa favoreceu o crescimento da planta e das folhas de Melissa officinalis L., comprovando que esse tipo de ambiente, favorece positivamente, o desenvolvimento dessa cultura. $\mathrm{Na}$ estufa as plantas são protegidas de condições adversas do clima e solo, evapotranspiração, 
Tabela 9. Porcentagem relativa média (\%) de citronelal obtido de folhas frescas de Melissa officinalis L. em função de sistemas de cultivos, adubações e épocas de plantio. UFU, Uberlândia, 20111.

\begin{tabular}{llll}
\hline & & ÉPOCA & \\
\hline SISTEMA & ADUBAÇÃO & Inverno & Verão \\
\hline Campo & Mineral & $19.328 \mathrm{aB}$ & $10.694 \mathrm{bA}$ \\
\cline { 2 - 4 } & Orgânica & $35.436 \mathrm{aA}$ & $4.182 \mathrm{bA}$ \\
\hline \multirow{2}{*}{ Estufa } & Mineral & $24.892 \mathrm{aA}$ & $1.144 \mathrm{bA}$ \\
\cline { 2 - 4 } & Orgânica & $17.572 \mathrm{aA}$ & $0.562 \mathrm{bA}$ \\
\hline CV(\%) & 40.23 & & \\
\hline
\end{tabular}

${ }^{1}$ Médias seguidas por letras distintas maiúsculas na coluna e minúsculas na linha se diferem pelo Teste de Tukey a 5\% de probabilidade

radiação solar, efeito direto das chuvas, lixiviação de nutrientes, entre outros, permitindo aumento da lâmina foliar como resposta a proteção (Andriolo, 2000). Portanto, o cultivo protegido forneceu condições favoráveis de luz, temperatura e umidade, para ganho em produtividade.

Quanto à adubação, o uso do esterco curtido apresentou-se satisfatório nas duas colheitas realizadas. Estudos semelhantes comprovaram que a adubação orgânica apresentou efeito positivo na produção de mudas de melissa e na altura de plantas, ao utilizar vermicomposto (Blank et al., 2005). Ainda se tratando do cultivo de aromáticas, Sousa et al. (2003) avaliou a produtividade de Lippia alba com esterco bovino, húmus, composto orgânico e NPK, também em estufa, obtendo resultados semelhantes com relação à produtividade de biomassa foliar.

Sobre o rendimento de óleo essencial, a excelente produtividade de óleo essencial no verão em relação ao inverno foi uma consequência da maior produção de biomassa na estufa em relação ao campo. Não houve influência significativa direta da adubação orgânica sobre o rendimento do óleo essencial. Silva et al. (2005), também verificando a influência da época no rendimento do óleo essencial de manjericão (Ocimum basilicum), concluiu que o óleo colhido em janeiro teve maior rendimento $(2,26 \%)$ que o óleo colhido em agosto $(1,06 \%)$. Logo, pode-se afirmar que as condições ambientais que propiciam maior desenvolvimento de biomassa são importantes para se obter maior rendimento e qualidade de óleo essencial e podem proporcionar lucratividade para o produtor por ser um óleo bem valorizado no mercado.

Sobre a composição, o padrão de qualidade dos óleos essenciais é uma das exigências do mercado consumidor (Blank et al., 2006). Para melissa, o óleo essencial mais valorizado deve apresentar em sua composição química o citral (neral + geranial) e citronelal como majoritários, e preferencialmente, a ausência de alcoóis terpênicos, tais com nerol, geraniol e citronelol.

$\mathrm{Na}$ época de verão, as condições do ambiente protegido favoreceram a formação do constituinte citral (Figuras 1 e 2). A maior quantidade de luz e umidade, além do controle do ambiente através da estufa proporcionou tal resultado. A intensidade luminosa é um fator que influencia a concentração bem como a composição química dos óleos essenciais. Como exemplo, para o desenvolvimento dos tricomas glandulares, estruturas vegetais que biossintetisam e armazenam o óleo essencial, é necessária a presença de luz (Morais, 2009). A maior produção de metabólitos secundários sob altos níveis de radiação solar é explicada devido ao fato de que as reações biossintéticas são dependentes de suprimentos de esqueletos carbônicos, realizados por processos fotossintéticos e de compostos energéticos que participam da regulação dessas reações (Taiz \& Zeiger, 2006). Logo, a maior disponibilidade de nutrientes pela adubação orgânica, associada ao controle da umidade do solo, permitiu o aumento da biomassa e a translocação de fotoassimilados para o metabolismo secundário nas plantas de melissa.

Por outro lado, a estiagem, com diminuição de umidade do solo, a queda da temperatura e o vento frio característicos da época fria e seca, possivelmente, proporcionaram condições desfavoráveis que levaram à queda da produção de citral. Esses fatores também ativaram a rota de produção do monoterpeno citronelal (Figura 2). Todos esses aspectos podem ter sido interpretados como uma possível situação de estresse, sendo a maior causa para a produção de tal constituinte. Assim como no estresse hídrico, as plantas ativam o metabolismo secundário para prevenção contra ataques de insetos e outros animais para sobrevivência. Martins et al. (2004) relata que os compostos monoterpênicos limoneno, citronelal, geraniol e neral, atuam na defesa química da planta contra a ação de predadores.

Nossos resultados concordam com Furlan et al. (2010) ao verificar a influência de fatores geográficos e microclimáticos na composição química dos óleos essenciais no estudo de Cymbopogon citratus. Nesse estudo, foi observado que o óleo essencial extraído de uma população cultivada em Pindamonhangaba-SP, (altitude média 
de $577 \mathrm{~m}, 1310 \mathrm{~mm}$ de precipitação no mês de coleta e temperatura média de $21^{\circ} \mathrm{C}$ ), apresentou concentração alta de citral (aproximadamente $96,0 \%$ ). Já na da região de Ibiúna-SP (altitude média de $850 \mathrm{~m}, 0 \mathrm{~mm}$ de precipitação no mês de coleta e temperatura média de $22^{\circ} \mathrm{C}$ ), a taxa de citral caiu para $40 \%$.

Para Camilo et al. (2009) em estudo também testando a influência de épocas, adubações e locais de cultivo na produção orgânica de Ocimum basilicum, o composto linalol foi predominante, tendo média de $76,5 \%$, seguido pelo acetato de linalol com percentual médio de $10,51 \%$ e 1,8-cineol em torno de 5,49\%. Para Botrel et al. (2010), estudando hortelã do campo, o constituinte químico majoritário do óleo essencial das plantas cultivadas em campo foi o germacra-4 (15),5,10(14)- trien-1 $\alpha$-ol, enquanto que o das plantas cultivadas em casa de vegetação foi o $\mathrm{y}$-muroleno. A diferença dos componentes dos óleos essenciais das plantas revela que o ambiente de cultivo é um fator importante para o teor e a composição química do óleo volátil, demonstrando a forte relação entre essas variáveis.

\section{CONCLUSÃO}

As condições do ambiente protegido propiciam melhor desenvolvimento de biomassa de melissa. As condições climáticas da época quente e úmida levam ao maior rendimento de óleo essencial e maior taxa de citral. A taxa de citronelal é maior na colheita de inverno.

\section{AGRADECIMENTOS}

Agradecimentos à FAPEMIG e ao CNPQ pelo financiamento desta pesquisa.

\section{REFERÊNCIA}

ADAMS, R.P. Identification of essential oil components by gás chromatography/mass spectroscopy. 4.ed. Carol Stream: Allured Publishing Corporation, 2007. 569p.

AMARAL, A.S. et al. Rendimento de matéria seca e de óleo essencial de Baccharis trimera com adubação química e orgânica. Revista de Ciências Agroveterinárias, v.9, n.1, p.20-28, 2010.

ANDRIOLO, J.L. Fisiologia da produção de hortaliças em ambiente protegido. Horticultura Brasileira, v.18, s.n., p.26-33, 2000.

BLANK, A.F. et al. Produção de mudas, altura e intervalo de corte em melissa. Horticultura Brasileira, v.23, n.3, p.780-784, 2005.

BLANK, A.F. et al. Efeitos da adubação química e da calagem na nutrição de melissa e hortelã-pimenta. Horticultura Brasileira, v.24, sn., p.195-198, 2006.

BOTREL, P.P. et al. Variações no teor e na composição volátil de Hyptis marrubioides epl. cultivada no campo e em casa de vegetação. Química Nova, v. 33, n.1, p.33-37, 2010.

BRANT, R.S. et al. Crescimento, teor e composição do óleo essencial de melissa cultivada sob malhas fotoconversoras. Ciência Rural, v. 39, n.5, p.14011407, 2009.

CAMILO, J. S.; LUZ, J.M.Q.; RESENDE, R.F. Produção agronômica de Ocimum basilicum L. em casa de vegetação e a campo nas épocas primavera-verão e outono-inverno. In: ENCONTRO INTERNO E XIII SEMINÁRIO DE INICIAÇÃO CIENTÍFICA, 2009, Uberlândia. Anais... Uberlândia: Universidade Federal de Uberlândia, 2009. p.1-10.

EHLERT, P.A.D. Épocas de plantio, idades e horários de colheita na produção e qualidade do óleo essencial de Lippia alba (Mill.) N. E. Br., quimiotipo limonenocarvona. 2003, 123p. Tese (Doutorado em Agronomia) - Universidade Estadual Paulista "Júlio De Mesquita Filho", Botucatu, São Paulo.

EMBRAPA. Empresa Brasileira de Pesquisa Agropecuária. Sistema brasileiro de classificação de solos. 3 ed. Rio de Janeiro: Embrapa-spi, 2013. 315p.

FERREIRA, D.F. SISVAR: sistema de análises de variância de dados balanceados: Programa de análises estatísticas e planejamento de experimentos. Versão 4.3. Lavras: UFLA. 2000.

FURLAN, M.R. et al. Variação dos teores de constituintes voláteis de Cymbopogon citratus (DC) Staf, Poaceae, coletados em diferentes regiões do Estado de São Paulo. Revista Brasileira de Farmacognosia, v.20, n.5, p.686-691, 2010.

FURLAN, M. R. Cultivo de plantas condimentares herbáceas. CETEC, out., 2007.

LORENZI, H.; MATOS, F.J.A. Plantas medicinais no Brasil: nativas e exóticas. 1.ed., Nova Odessa: Instituto Plantarum, São Paulo, 544 p. 2002.

MAIA, J.G.S.; ANDRADE, E.H.A. Database of the Amazon aromatic plants and their essential oils. Química nova, v. 32, n.3, p. 595-622, 2009.

MARTINS, M.B.G. et al. Caracterização anatômica da folha de Cymbopogon citratus (DC) Stapf (Poaceae) e perfil químico do óleo essencial. Revista Brasileira de Plantas Medicinais, v.6, n.3, p.20-29, 2004.

MARTINS, E. R.; FIGUEIREDO, L. S. Cultivo de plantas medicinais. IN: LEITE, J. P. V. Fitoterapia: bases científicas e tecnológicas. São Paulo: Atheneu, 2009. p. 143-167.

MCLAFFERTY, F.W.; STAUFFER, D.B. The Willey /NBS Registry of Mass Spectral Data. 2.ed. New York: John Willey, 563p. 1989.

MORAIS, L.A.S. Influência dos fatores abióticos na composição química dos óleos essenciais. Horticultura Brasileira, v.27, s.n., p.4050-4063, 2009.

OZTURK, A. et al. Effects of salt stress and water deficit on Melissa officinalis L. Pakistan Journal of Botany, v.36, n.4, p.787-792, 2004.

PAVIANI, L.C. Extração com $\mathrm{CO}_{2}$ a altas pressões e fracionamento do óleo essencial de capim-limão utilizando peneiras moleculares. 2004. 245p. Tese (Doutorado em Agronomia), Faculdade de Engenharia de Alimentos - Universidade Regional Integrada do Alto Uruguai e das Missões, Erechim, Rio Grande do Sul. 
SALES, J.F. et al. Acúmulo de massa, teor foliar de nutrientes e rendimento de óleo essencial de hortelãdo-campo (Hyptis marrubioides Epl.) cultivado sob adubação orgânica. Bioscience Journal, v.25, n.1, p.60-68, 2009.

SARI, A.O.; CEYLAN, A. Yield characteristics and essential oil composition of lemon balm (Melissa officinalis L.) grown in the Aegean Region of Turkey. Turk Journal of Agriculture, v.26, s.n., p.217-224, 2002.

SILVA, F. et al. Basil conservation affected by cropping season, harvest time and storage period. Pesquisa Agropecuária Brasileira, v.40, s.n., p.323-328, 2005.
SOUSA, A.H. et al. Produção de biomassa na parte aérea da erva cidreira (Melissa ssp.) em função de doses de esterco bovino, húmus de minhoca, composto orgânico e NPK em casa de vegetação. Revista de Biologia e Ciências da Terra, v.3, n.2, p.233-236, 2003

TAIZ, L.; ZEIGER, E. Fisiologia vegetal. 6.ed. Rio de Janeiro: Ed. Artmed., 2006, 720p.

VALMORBIDA, J. et al. Rendimento e composição química de óleos essenciais de Mentha piperita L. cultivada em solução nutritiva com diferentes concentrações de potássio. Revista Brasileira de Plantas Medicinais, v.8, n.4, p.56-61, 2006. 